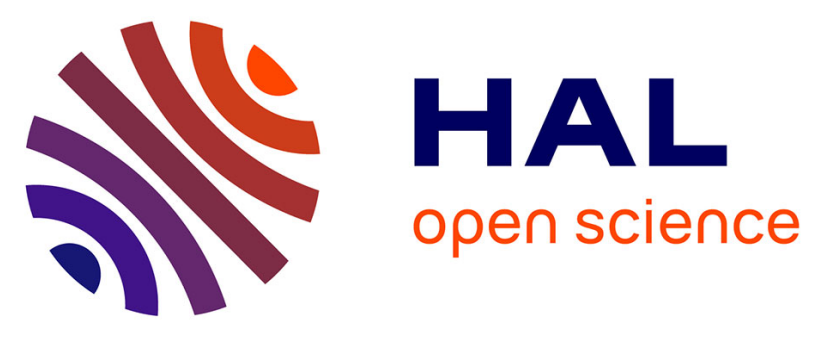

\title{
Efficient light harvesting anionic heptamethine cyanine-[60] and [70]fullerene hybrids
}

Carmen Villegas, Evangelos Krokos, Pierre-Antoine Bouit, Juan Luis Delgado, Dirk m. Guldi, Nazario Martin

\section{- To cite this version:}

Carmen Villegas, Evangelos Krokos, Pierre-Antoine Bouit, Juan Luis Delgado, Dirk m. Guldi, et al.. Efficient light harvesting anionic heptamethine cyanine-[60] and [70]fullerene hybrids. Energy \& Environmental Science, 2011, 4, pp.679-684. 10.1039/C0EE00497A . hal-01443303

\section{HAL Id: hal-01443303 \\ https://hal-univ-rennes1.archives-ouvertes.fr/hal-01443303}

Submitted on 17 Jul 2020

HAL is a multi-disciplinary open access archive for the deposit and dissemination of scientific research documents, whether they are published or not. The documents may come from teaching and research institutions in France or abroad, or from public or private research centers.
L'archive ouverte pluridisciplinaire HAL, est destinée au dépôt et à la diffusion de documents scientifiques de niveau recherche, publiés ou non, émanant des établissements d'enseignement et de recherche français ou étrangers, des laboratoires publics ou privés. 


\title{
Efficient Light harvesting Anionic Heptamethine Cyanine-[60] and [70]Fullerene Hybrids.
}

\author{
Carmen Villegas, ${ }^{a}$ Evangelos Krokos, ${ }^{b}$ Pierre-Antoine Bouit, ${ }^{c}$ Juan Luis Delgado, ${ }^{a c}$ Dirk M. Guldi, ${ }^{* b}$ \\ ${ }_{5}$ Nazario Martín ${ }^{a c *}$
}

New anionic fullerene-heptamethine conjugates absorbing as far as $900 \mathrm{~nm}$ have been synthesized and fully characterized by 10 physicochemical means. In terms of electron transfer, we have succeded in realizing the rarely occurring scenario of a charge transfer commencing with a higher excited state. Kinetic studies reveal that charge separation and charge recombination dynamics occur in the normal and inverted Marcus region, respectively.

\section{Introduction}

15 Artificial systems that mimic the elegant operations of the photosynthetic process, namely light-harvesting, light-funnelling, charge separation and charge-shift, converting light into useful electrochemical potentials, have been at the forefront of extensive research in recent years, predominantly in the area of 20 optoelectronics. ${ }^{1}$ Fullerenes, three-dimensional carbon allotropes, exhibit attributes that are particularly well suited for electron transfer processes. Videlicet, their notable electron accepting properties $^{2}$ and exceptionally low reorganization energies in electron transfer processes ${ }^{3}$ render them excellent building blocks 25 for electron donor-acceptor conjugates. In fact, fullerenes are known to accelerate charge separation, midst retarding charge recombination. The affluent chemistry that fullerenes feature ${ }^{4}$ enables their covalent linking to a diverse collection of chromophors - including porphyrins, ${ }^{4}$ phthalocyanines ${ }^{5}$ or ${ }_{30}$ perylenes $^{6}$ that function as light harvesting antennas and electron donors.

The aforementioned systems have been thoroughly studied despite the fact that their absorptions rarely extend beyond 700 $\mathrm{nm}$. Nevertheless, electron donor-acceptor systems containing 35 near-infrared absorbing dyes are of pivotal importance because of the amount of near infrared radiation in the solar spectrum. Charge transfer efficiency, however, may be at peril when chromophores with light-harvesting abilities that span beyond $700 \mathrm{~nm}$ are being employed. To this end, the interactions 40 between structure and charge transfer reactivity are expected to be as crucial as the parameters met in conventional systems, essentially the energy gap between the higher $\left(\mathrm{S}_{2}\right)$ and the lowest $\left(\mathrm{S}_{1}\right)$ singlet excited state as well as the lifetime of $\mathrm{S}_{2}$. This prompted us to study the electronic interactions between 45 fullerenes and heptamethine cyanine dyes. Cyanines manifest remarkable optical properties in the infrared section of the solar spectrum and noteworthy chemical stability. These traits, which render cyanines more than adequately suited to be utilized for exploring the prospect of near-infrared photoinduced charge 50 transfer reactions, are due to a delocalized charge on a $\pi$ - conjugated bridge featuring an odd number of carbons. ${ }^{7}$ We have previously reported on molecular electron donor-acceptor conjugates containing cationic cyanines and fullerenes (Figure 1). In that study, time resolved transient absorption measurements 55 revealed that photoexcitation is followed by charge transfer evolving from higher singlet excited states of the heptamethine cyanine as electron donor to an either covalently linked $\mathrm{C}_{60}$ or $\mathrm{C}_{70}$ as electron acceptor. ${ }^{8}$ This prominent photophysical event ${ }^{9}$ introduced new possibilities in electron transfer reactions that ${ }_{60}$ could be beneficial for photovoltaics. In order to ascertain the feasibility of implementing near-infrared absorbing heptamethine dyes as light harvesters for photovoltaics, molecular PV cells were prepared, in which a mixture of hepamethine dyes and $\mathrm{PCBM}$ as fullerene derivative was used as the only active layer. ${ }^{10}$

65 Notwithstanding other strongly absorbing cyanines endowed with a negative charge, we decided to focus on an anionic polymethine cyanine absorbing as far as $900 \mathrm{~nm}$. These compounds, displaying maxima in the NIR region of the solar spectrum, intrigued us to probe them in conjunction with $\mathrm{C}_{60}(\mathbf{6}$, 70 scheme 1$)$ as well as $\mathrm{C}_{70}(\mathbf{7}$, scheme 1$)$ as photo- and redox-active building blocks and to compare their properties with their previously studied cationic analogs.

Herein we describe the preparation of new electron donor acceptor conjugates using an anionic cyanine and fullerenes. The 75 slow internal conversion within the light harvesting polymethine and the strong electronic coupling between the individual constituents are the basis for powering a charge transfer from higher excited state of the polymethine. 

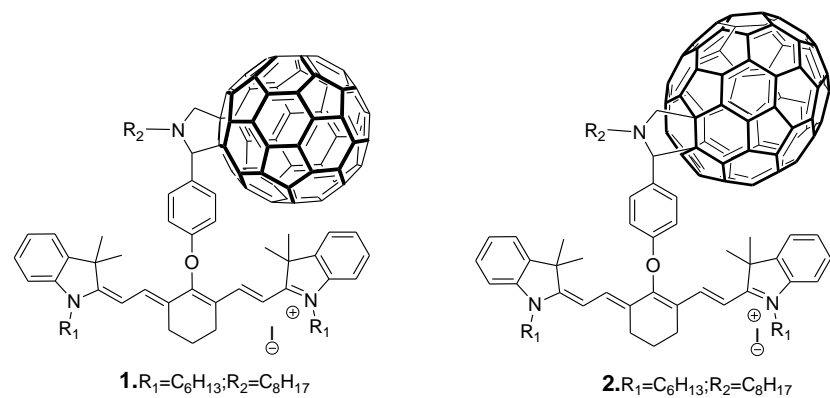

Figure 1. Previously synthesized cyanine- $\mathrm{C}_{60}$ conjugate $\mathbf{1}$ and cyanine-C70 2 .

\section{Results and Discussion}

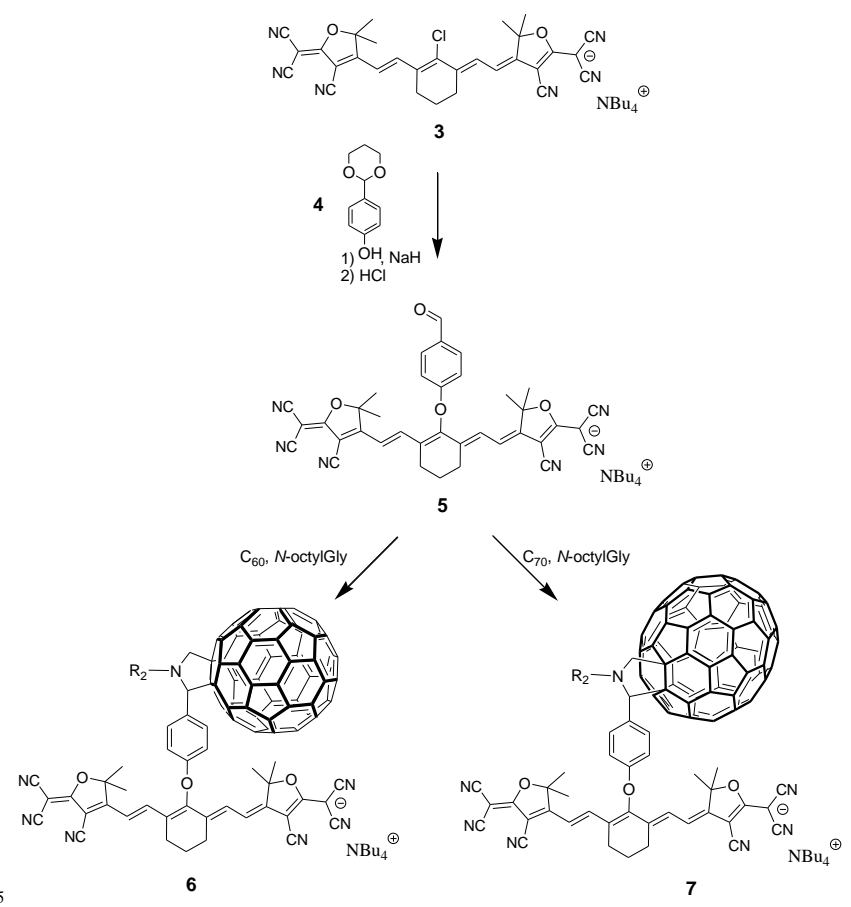

Scheme 1. Synthesis of fullerene-heptamethine conjugates 6 and 7.

\section{Synthesis and Characterization}

The synthesis of the new polymethine cyanine-fullerene electron donor-acceptor conjugates $\mathbf{6}$ and 7 was carried out in two steps, starting from previously described heptamethine cyanine $(\mathbf{3})^{11}$ as it is depicted in Scheme $1 .^{8}$ The introduction of the $p$ 15 hydroxybenzaldehyde unit to the chloro-heptamethine cyanine (3) was achieved from $\mathbf{3}$ and $\mathbf{4}$, by substitution of the meso-chlorine atom to form 5 (Scheme 1). Thus, reaction of formyl-cyanine $\mathbf{5}$ with either $\mathrm{C}_{60}$ or $\mathrm{C}_{70}$ in the presence of $N$-octylglycine and chlolorobenzene as solvent, ${ }^{12}$ afforded $\mathbf{6}$ and $\mathbf{7}$ as deep green 20 solids in $70 \%$ and $40 \%$ yields, respectively. As expected, 7 was obtained and studied as a mixture of isomers due to the multiple possibilities of addition of azomethine ylides to $\mathrm{C}_{70}$. The structures of 6 and 7 were confirmed by ${ }^{1} \mathrm{H}$ and ${ }^{13} \mathrm{C}-\mathrm{NMR}$. The presence of the conjugated cyano groups was confirmed by the 25 intense band at $2207 \mathrm{~cm}^{-1}$ in the FT-IR spectra. The ${ }^{1} \mathrm{H}-\mathrm{NMR}$ spectrum of $\mathbf{6}$ shows, in addition to the aromatic protons, the expected protons of the pyrrolidine ring, and the presence of the vinylic protons relating to the cyanine moiety. Furthermore, high resolution MS measurements confirmed the formation of both 30 dyads, $6\left([\mathrm{M}]^{-}=1465,35757\right.$ (calcd. $\left.\mathrm{C}_{106} \mathrm{H}_{46} \mathrm{~N}_{7} \mathrm{O}_{3}: 1465,36999\right)$ and $7[\mathrm{M}]^{-}=1585,36895$ (calcd. $\mathrm{C}_{116} \mathrm{H}_{46} \mathrm{~N}_{7} \mathrm{O}_{3}$ : 1585,37000) see SI for details.

\section{Optical properties}

The absorption properties of compounds $\mathbf{5}, \mathbf{6}$, and $\mathbf{7}$ were 35 studied in dichloromethane as solvent. All the compounds display an intense absorption band in the near-infrared $(\varepsilon \sim 300000$ $\mathrm{L} / \mathrm{mol} / \mathrm{cm}$ ) centered at $896 \mathrm{~nm}$, due to the presence of the anionic polymethine cyanine. $\mathbf{6}$ and $\mathbf{7}$ display also absorption bands in the UV-visible, which are the typical absorption features 40 for both $\mathrm{C}_{60}$ and $\mathrm{C}_{70}$, respectively (Figure 2). As expected, 6 and 7 display a longer absorption maxima shifted towards longer wavelength, when compared to the cationic analogues $\mathbf{1}$ and $\mathbf{2}$, as already observed in previous studies on simpler related systems. ${ }^{11}$

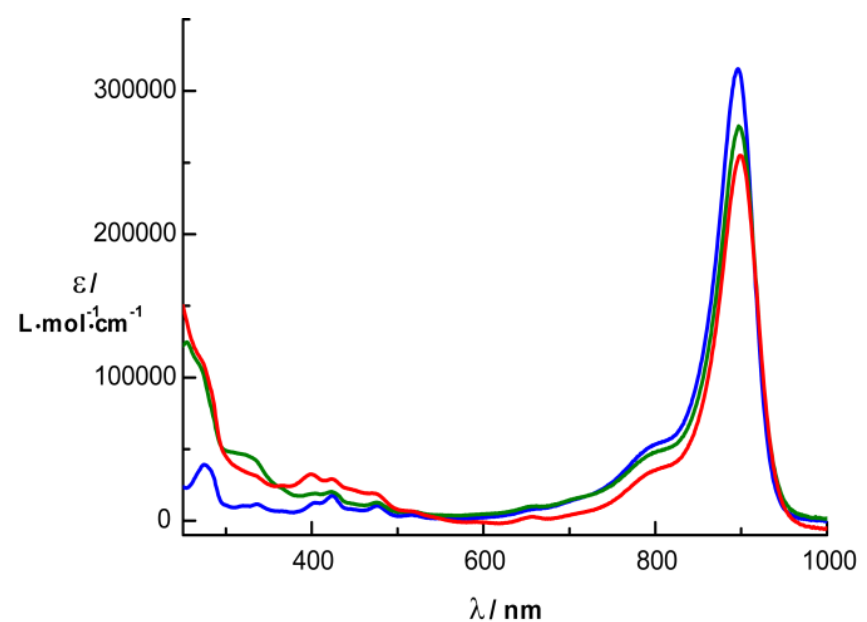

${ }_{45}$ Figure 2. Absorption spectra of 5 (blue), 6 (green), and 7 (red) recorded in dichloromethane.

\section{Electrochemistry}

The electrochemical properties of $\mathbf{5}, \mathbf{6}$, and $\mathbf{7}$ have been studied at room temperature by means of cyclic voltammetry. As 50 described for similar anionic cyanine heptamethines, ${ }^{10} \mathbf{5}$ reveals an amphoteric redox character with reversible one-electron reduction processes at -0.94 and $-1.76 \mathrm{~V}$. One-electron oxidation processes, on the other hand, are noted at $+0.18 \mathrm{~V}-$ fully reversible - and $0.87 \mathrm{~V}$ - irreversible. 6 displays additionally 55 three reversible one-electron reductions, due to the presence of $\mathrm{C}_{60}$, at $-0.95,-1.32$, and $-1.88 \mathrm{~V}$ (Figure 3 ). In 7, the one-electron reductions for $\mathrm{C}_{70}$ were detected at $-0.94,-1.31$, and $-1.78 \mathrm{~V}$. The characteristic reductions of the anionic cyanine moiety ( -0.94 and $-1.76 \mathrm{~V})$ are superimposed to the first and third fullerene 60 reduction, thus increasing the intensity of these steps in 
comparison with the second reduction $(-1.32$ or $-1.31 \mathrm{~V})$ (Figure $3)$. On the oxidation side, 6 and 7 display the characteristic oxidations of the cyanine moiety $(6:+0.16,+0.88 \mathrm{~V} ; 7:+0.16$, $+0.86 \mathrm{~V}) .6$ displays similar electrochemical properties to its 5 cationic analogue $\mathbf{1}$, recorded under the same experimental conditions (see table S1). In both cases, the first reduction potential of the cyanine is close to the first reduction potential of the fullerenopyrrolidine. These data suggest that the LUMOs of both electro-active units are energetically close. The 10 electrochemical properties of 5, 6, and 7 were also studied in benzonitrile as solvent. With these data in hands we have derived radical ion state pair energies of $1.11 \mathrm{eV}(6)$ and $1.13 \mathrm{eV}(7)$ in benzonitrile.
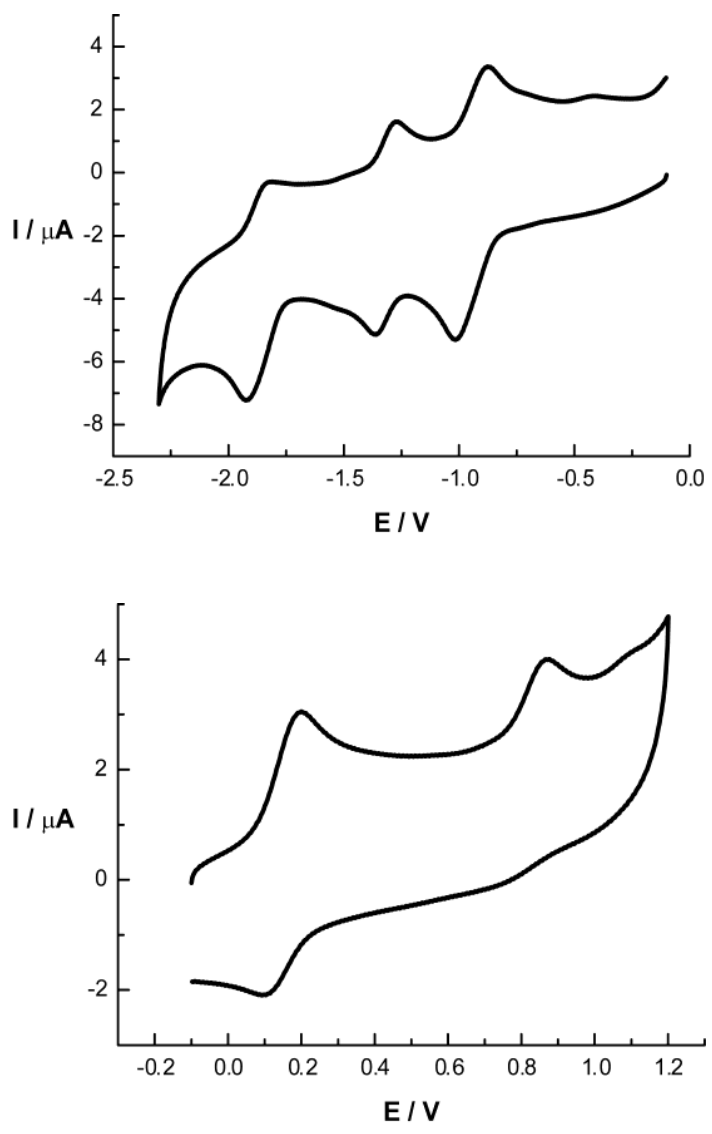

Figure 3. Cyclic voltammograms of $\mathbf{6}$; top (reduction), bottom (oxidation) - V vs $\mathrm{Ag} / \mathrm{AgNO}_{3} ; \mathrm{GCE}$ as the working electrode; 0.1 M TBAP; $o$-DCB/MeCN (4:1); scan rate $100 \mathrm{mV} / \mathrm{s}$.

Photophysical Studies Laser flash photolysis experiments were 20 carried out, employing excitation wavelengths of 387 and $775 \mathrm{~nm}$ to photoactivate $\mathrm{C}_{60}$ or $\mathrm{C}_{70}$ and the cyanine moiety, respectively. Excitation of $\mathrm{C}_{60}$ or $\mathrm{C}_{70}$ leads to the generation of their singlet excited states with characteristic absorption maxima at $610 / 920$ and $610 / 1360 \mathrm{~nm}$, respectively. Intersystem crossing to the 25 corresponding triplet manifolds is the predominant deactivation pathways of these singlet excited states. In fact, the singlet lifetimes are quite short and range from 0.7 to $1.4 \mathrm{~ns}$.
Characteristics of the triplet excited states are maxima at $700 \mathrm{~nm}$ for $\mathrm{C}_{60}$ and $970 \mathrm{~nm}$ for $\mathrm{C}_{70}$.

30 At first glance, the transient absorption spectra upon $387 \mathrm{~nm}$ excitation of $\mathbf{5}$ in dichloromethane or benzonitrile are dominated by strong ground state bleaching centered around $920 \mathrm{~nm}$ (Figure 4). A closer analysis reveals that the instantaneously formed higher singlet excited state of 5 features maxima at 490, 600, and $35990 \mathrm{~nm}$, minima at 565, 630, 735, and $1400 \mathrm{~nm}$, and broad bleach between 820 and $955 \mathrm{~nm}$. With a lifetime of 4.4 ps these features transform rapidly into those of the lowest singlet excited state with distinct maxima at 520, 585, 625, and $1240 \mathrm{~nm}$ plus distinct minima at 730 and $920 \mathrm{~nm}$. Next, the decay of the singlet excited 40 state follows within approximately 2000 ps. Population of the higher lying singlet excited states was bypassed upon $775 \mathrm{~nm}$ excitation, which leads to the rapid formation (>0.5 ps) of the lowest singlet excited state. The lifetime of the correspondingly formed singlet excited state as determined from a 45 multiwavelenght analysis is $1.9 \mathrm{~ns}\left(5.2 \times 10^{8} \mathrm{~s}^{-1}\right)$.
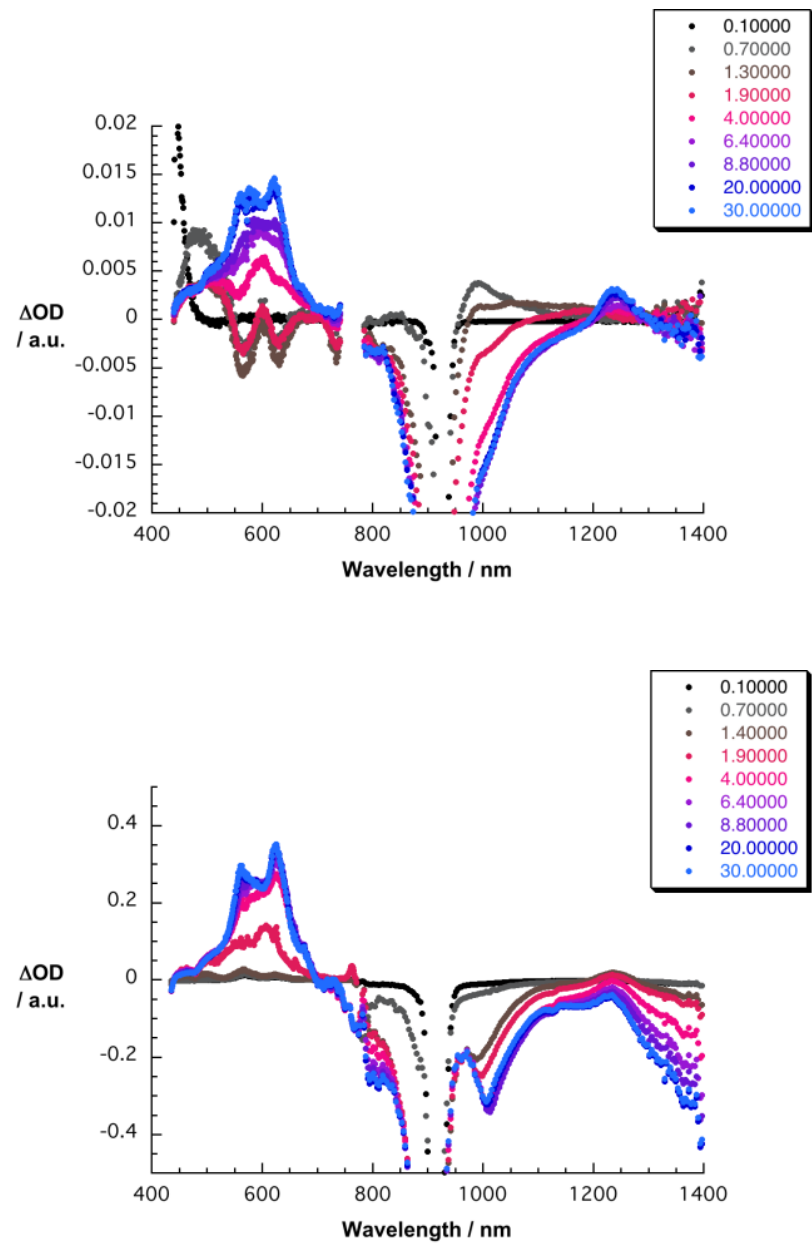

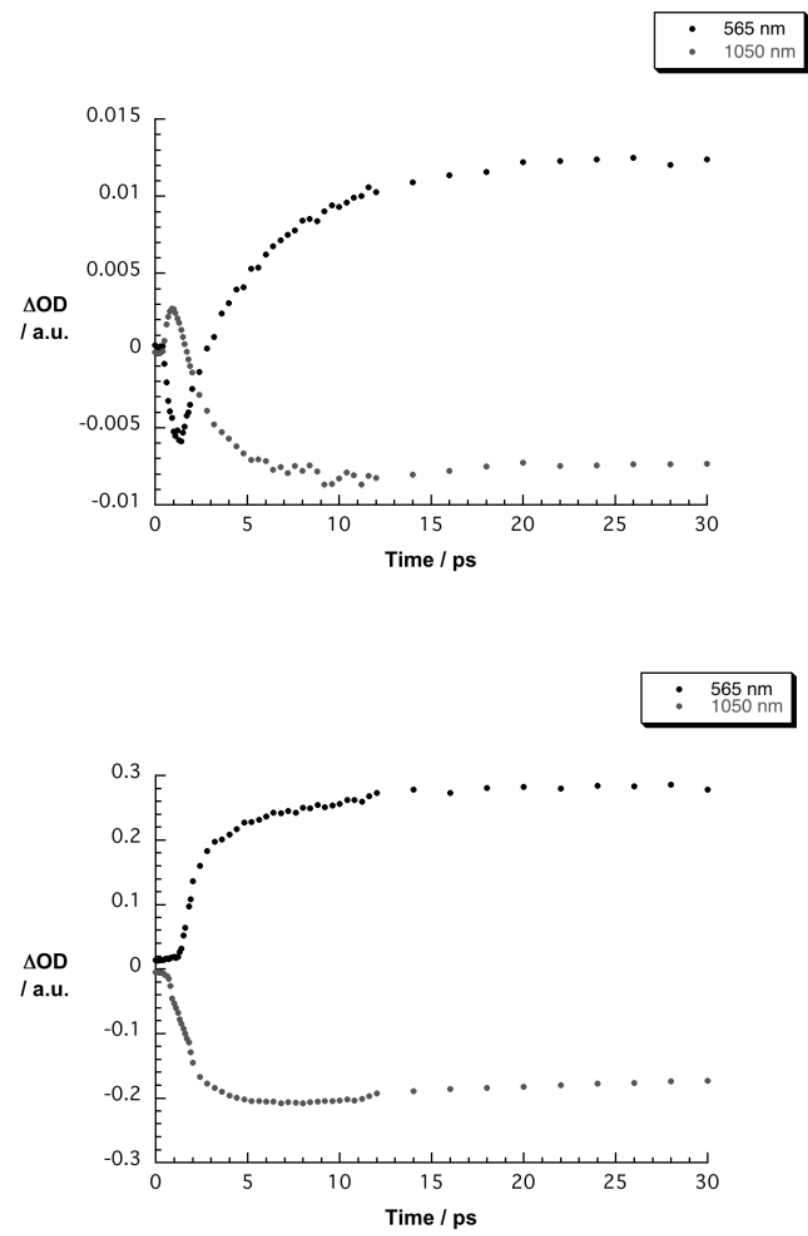

Figure 4: Upper part - differential absorption spectra (visible and near-infrared) obtained upon femtosecond flash photolysis (387 $5 \mathrm{~nm}$ ) of $\mathbf{5}$ in benzonitrile with several time delays between 0 and 42 ps at room temperature - see Figure legend for details. Upper central part - differential absorption spectra (visible and nearinfrared) obtained upon femtosecond flash photolysis $(775 \mathrm{~nm})$ of 5 in benzonitrile with several time delays between 0 and 42 ps at 10 room temperature - see Figure legend for details. Lower central part - time-absorption profiles of the spectra shown in the upper part at 565 and $1050 \mathrm{~nm}$ monitoring the internal conversion. Lower part - time-absorption profiles of the spectra shown in the upper central part at 565 and $1050 \mathrm{~nm}$ monitoring the internal 15 conversion.

In accordance with the absorption spectra that reveal a partition of 5 and $\mathrm{C}_{60}$ or $\mathrm{C}_{70}$ absorption of 1:1 for $\mathbf{6}$ and 3:1 for 7 at $387 \mathrm{~nm}$ - see Figure 2 - we note upon photoexcitation of $\mathbf{6}$ and 7 at this wavelength nearly exclusively the transients of the higher singlet 20 excited state features of $\mathbf{5}$ - vide supra. Owing to the slow internal conversion and vibrational relaxation in $\mathbf{5}$ the latter start to transform in benzonitrile into main maxima at 520, 545, 600, $655,1000,1015,1085$, and $1235 \mathrm{~nm}(6)$ as well as 520, 545, 600, $655,1000,1085,1235$, and $1300 \mathrm{~nm}(7)$ - the radical ion pair
${ }_{25}$ states - before the population of the lowest singlet excited state (Figures 5 and S10). Spectroelectrochemically and pulse radiolytically generated one-electron oxidized form of $\mathbf{5}$ further support the notion of radical ion pair state formation (Figure S11). In fact, these are in perfect agreement with the transient 30 maxima observed at 520,600, and $1240 \mathrm{~nm}$. The transient features, on the other hand, at around 1015 and $1300 \mathrm{~nm}$ are in accordance with previous work by pulse radiolysis assigned to the one-electron reduced forms of $\mathrm{C}_{60}$ and $\mathrm{C}_{70}$, respectively. From multi-wavelength analyses we have derived charge separation 35 (i.e., $k_{\mathrm{CS} 1}$ ) and charge recombination dynamics (i.e., $k_{\mathrm{CR}}$ ) of 3 ps $\left(3.3 \times 10^{11} \mathrm{~s}^{-1}\right)$ and $400 \mathrm{ps}\left(2.5 \times 10^{9} \mathrm{~s}^{-1}\right)$ in 6 as well as 4 ps $(2.5 \mathrm{x}$ $\left.10^{11} \mathrm{~s}^{-1}\right)$ and $430 \mathrm{ps}\left(2.3 \times 10^{11} \mathrm{~s}^{-1}\right)$ in 7 . Remarkable is the competition between charge transfer (i.e., 3 ps) and internal conversion / vibrational relaxation (i.e., $2.5 \mathrm{ps}$ ). In light of this

40 kinetic competition, the radical ion pair state and the lowest singlet excited state are formed with 45.5 and $54.5 \%$, respectively. In fact, during the early times of our femtosecond experiments the accordingly formed singlet excited states of $\mathbf{5}$ are discernable - a shoulder at 520 and the $1250 \mathrm{~nm}$ maximum. The 45 latter reveals shortened lifetimes of approximately 12 ps for 6 and 18 ps for 7 in benzonitrile, when compared to the intrinsic lifetime of $\mathbf{5}$ to generate the same radical ion pair state that originated from the higher singlet excited state. In turn, we have deduced from the latter charge separation kinetics (i.e., $k_{\mathrm{CS} 2}$ ) of ${ }_{50} 8.3 \times 10^{10} \mathrm{~s}^{-1}$ for 6 and $5.5 \times 10^{10} \mathrm{~s}^{-1}$ for 7. Such lifetimes suggest charge separation (i.e., $k_{\mathrm{CS} 1}, k_{\mathrm{CS} 2}$ ) and charge recombination dynamics (i.e., $k_{\mathrm{CR}}$ ) that are in the normal and inverted region of the Marcus parabola, respectively. Relating these charge separation kinetics to the intrinsic decay of the photoexcited 55 cyanine moiety $\left(5.2 \times 10^{8} \mathrm{~s}^{-1}\right)$ we conclude charge transfer efficiencies close to unity, that is, nearly $100 \%$.

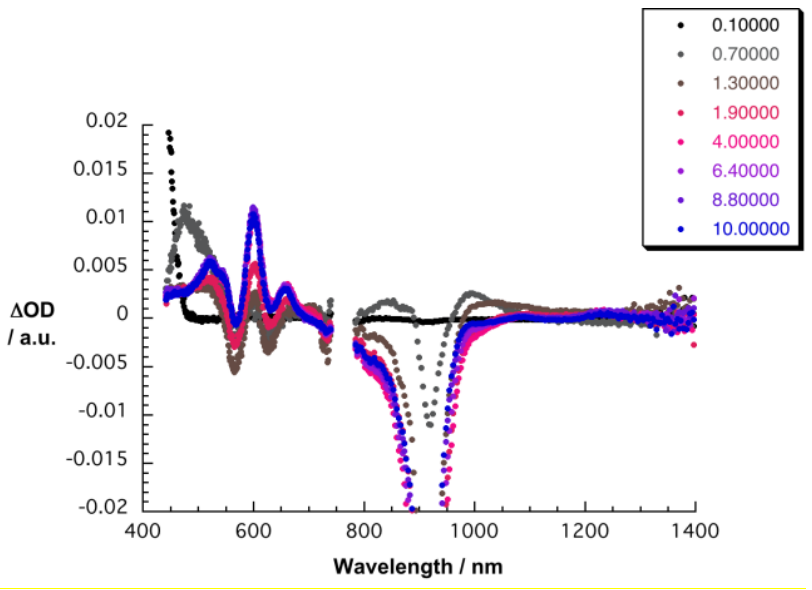



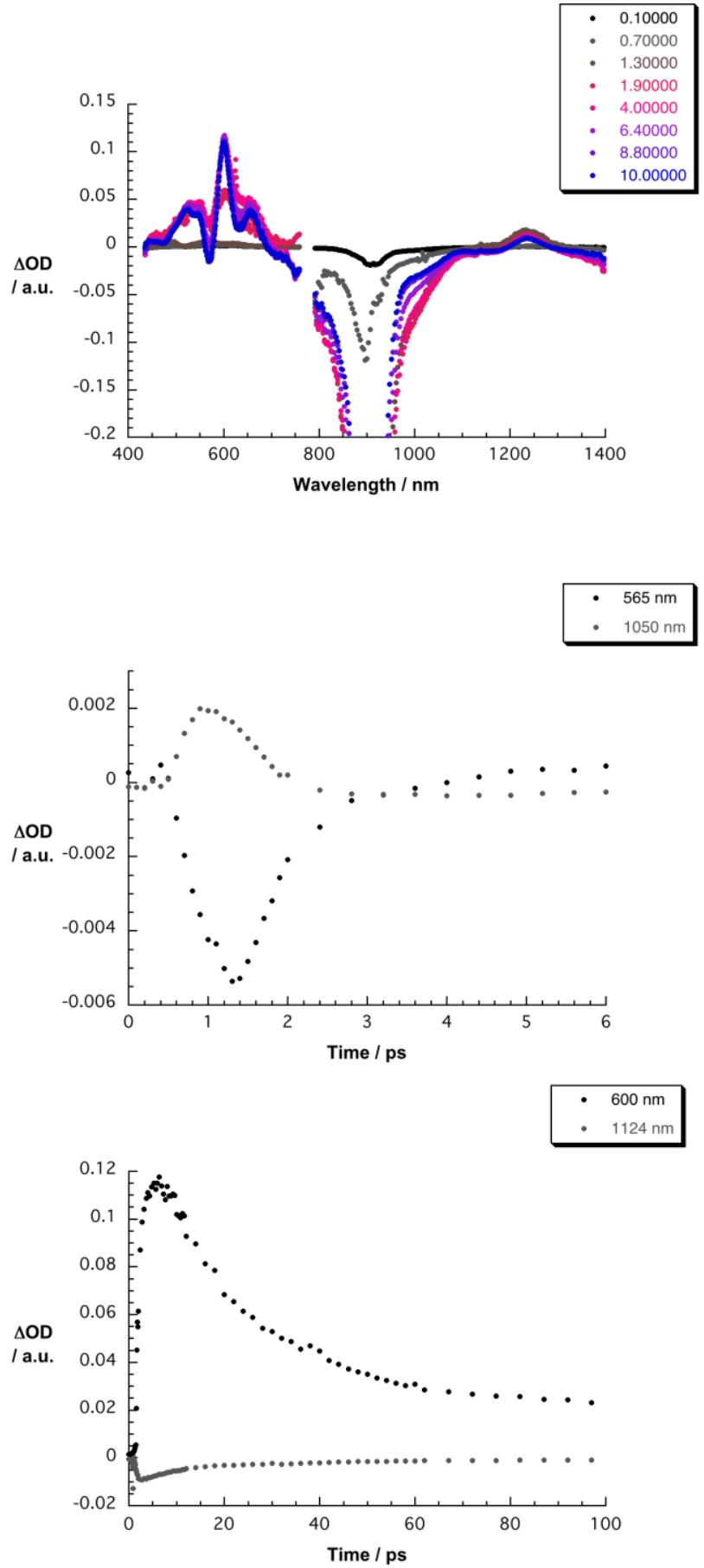

Figure 5: Upper part - differential absorption spectra (visible and 5 near-infrared) obtained upon femtosecond flash photolysis (387 $\mathrm{nm})$ of 6 in benzonitrile with several time delays between 0 and 22 ps at room temperature - see Figure legend for details. Upper central part - differential absorption spectra (visible and nearinfrared) obtained upon femtosecond flash photolysis $(775 \mathrm{~nm})$ of ${ }_{10} 6$ in benzonitrile with several time delays between 0 and 22 ps at room temperature - see Figure legend for details. Lower central part - time-absorption profiles of the spectra shown in the upper part at 565 and $1050 \mathrm{~nm}$ monitoring the charge separation.
Lower part - time-absorption profiles of the spectra shown in the 15 upper central part at 600 and $1124 \mathrm{~nm}$ monitoring the charge separation and charge recombination.

In line with reference experiments, exciting 6 and 7 at $775 \mathrm{~nm}$ the directly and solely formed singlet excited state features emerge at the conclusion of the photoexcitation. In particular, maxima at 20 520, 585, 625, and $1240 \mathrm{~nm}$ plus distinct minima at 730 and 920 $\mathrm{nm}$ are discernable. In contrast, to the slow singlet excited state deactivation that was seen for $\mathbf{5}$, these features are short-lived in $\mathbf{6}$ and 7. In fact, they decay $\left(k_{\mathrm{CS} 2}\right)$ in benzonitrile for 6 with $15 \mathrm{ps}$ $\left(6.7 \times 10^{10} \mathrm{~s}^{-1}\right)$, while $13 \mathrm{ps}\left(7.7 \times 10^{10} \mathrm{~s}^{-1}\right)$ was derived for 7 , to 25 yield the radical ion pair state features. The latter include for 6 the spectroscopic markers at 600, 1015, and $1100 \mathrm{~nm}$, while 7 exhibits the markers at 600,1100 , and $1300 \mathrm{~nm}$.

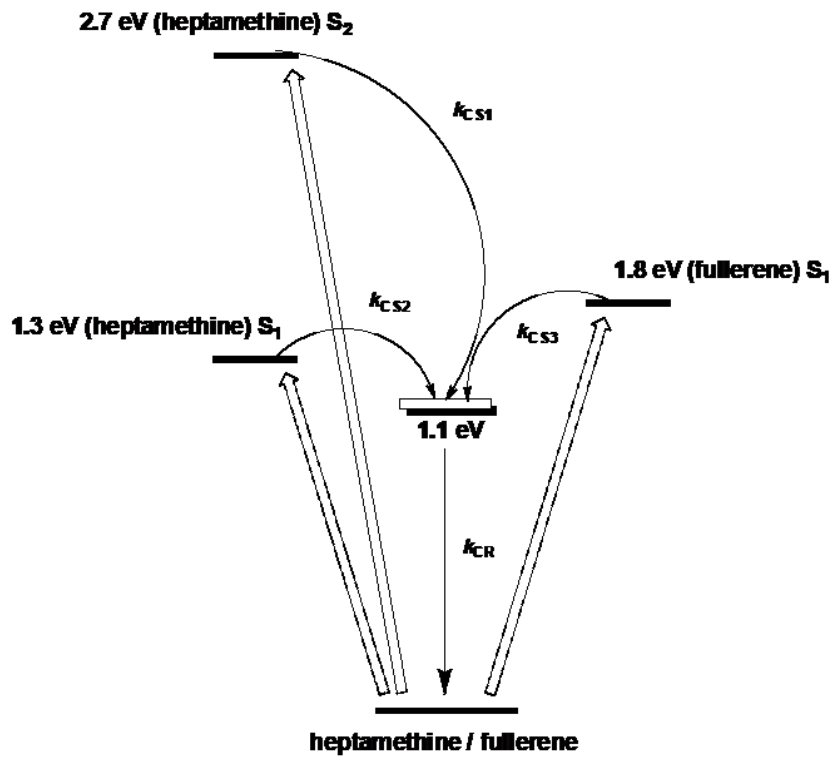

Figure 6: Energy diagram illustrating the different excitation, 30 charge separation $\left(k_{\mathrm{CS} 1}, k_{\mathrm{CS} 2}, k_{\mathrm{CS} 3}\right)$ and charge recombination $\left(k_{\mathrm{CR}}\right)$ pathways of anionic heptamethine cyanine-fullerene derivatives (6 and 7).

\section{Conclusions}

In summary, we have carried out the synthesis of a new type of 35 fullerene derivatives bearing covalently connected an anionic heptamethine cyanine moiety. The new molecule is a powerful light harvesting system absorbing at $900 \mathrm{~nm}$ with very high extinction coefficients. Remarkably, photoexciting at $387 \mathrm{~nm}$ leads to the formation of higher singlet excited states in 40 compounds 6 and 7, which is followed by a kinetic competition between the charge separation and the internal deactivation to the lowest singlet excited state. The measured values reveal that charge separation and charge recombination dynamics occur in the normal and inverted region of the Marcus parabola, 
respectively. Nevertheless, the charge recombination is fast a fact that is due to the presumably large reorganization energy that is imposed by the anionic heptamethine cyanine moiety.

5 Acknowledgments. Forschungsgemeinschaft (Grant SFB 583), Cluster of Excellence "Engineering of Advanced Materials" is gratefully acknowledged. This work has been supported by the European Science Foundation (SOHYD, MAT2006-28170-E), the MEC of Spain (CT2008-00795/BQU, and Consolider-Ingenio 10 2010C-07-25200, Nanociencia Molecular) and Comunidad de Madrid (MADRISOLAR-2, S2009/PPQ-1533). J.L.D. thanks the MICINN of Spain for a Ramón y Cajal Fellowship

\section{Notes and references}

${ }^{a}$ Departamento de Química Orgánica,Facultad de Ciencias Químicas, 15 Universidad Complutense de Madrid, Ciudad Universitaria s/n, 28040, Madrid (Spain) Fax: (+34) 91-394-4103, ; Tel: (+34) 91-394-4227;

E-mail:nazmar@quim.ucm.es

${ }^{b}$ Department of Chemistry and Pharmacy \&Interdisciplinary Center of Molecular Materials (ICMM) Friedrich-Alexander-University Erlangen-

20 Nuremberg Egerlandstr. 3, 91058 Erlangen (Germany)

Fax: (+49) 9131-85-28307

E-mail: dirk.guldi@chemie.uni-erlangen.de

${ }^{c}$ IMDEA-Nanociencia, Facultad de Ciencias, Módulo C-IX, $3^{a}$ planta, Ciudad Universitaria de Cantoblanco, 28049 Madrid (Spain).

25

$\dagger$ Electronic Supplementary Information (ESI) available: Synthesis and characterization of the new compounds as well as additional electrochemical and photophysical data.

${ }^{1}$ For some recent special issues, see: (a) Special issue on "Organic Photovoltaics", J.-L. Bredas, J. R. Durrant, eds. Acc. Chem., Res., 2009, 42, 1689; (b) Special issue on "Renewable Energy", D. Nocera, D. M. Guldi, eds. Chem. Soc. Rev 2009, 38, 1; c) B. C. Thompson, J. M. J. Frechet, Angew. Chem. Int. Ed., 2008, 47, 58; d) J. L. Delgado, P.-A. Bouit, S. Filippone, M.A. Herranz, N. Martín, Chem. Commun., 2010, 46, 4853; e) I. Riedel, E. von Hauff, J. Parisi, N. Martín, F. Giacalone V. Diakonov, Adv. Funct. Mater., 2005, 15, 1979, f) J.L. Delgado, E. Espíldora, M. Liedtke, A. Sperlich, D. Rauh, A. Baumann, C. Deibel, V. Dyakonov, N. Martín, Chem. Eur. J., 2009, 15, 13474. e) N. Martín, Chem. Commun. 2006, 2093.

2 a) L. Echegoyen, L.E. Echegoyen, Acc. Chem. Res. 1998, 31, 593; (b) C. A. Reed, R. D. Bolskar, Chem. Rev., 2000, 100, 275.

${ }^{3}$ a) For a recent review article, see: G. Accorsi, N. Armaroli, J. Phys Chem C, 2010, 114, 1385, and references cited therein. b) D.M. Guldi; K.-D. Asmus, J. Am. Chem. Soc. 1997, 119, 5744 (b) S. Fukuzumi, K. Ohkubo, H. Imahori, D.M. Guldi, Chem.-Eur. J., 2003, 9, 1585.

${ }^{4}$ a) F. Spänig, M. Ruppert, J. Dannhäuser, A. Hirsch, D. M. Guldi, J. Am. Chem. Soc., 2009, 131, 9378, b) D. I. Schuster, K. Li, D. M. Guldi, A. Palkar, L. Echegoyen, C. Stanisky, R. James Cross, M. Niemi, N. V. Tkachenko, H. Lemmetyinen, J. Am. Chem. Soc., 2007, 129, 1597, c) J.-F. Nierengarten, C. Schall, J.-F. Nicoud, Angew. Chem. Int. Ed., 1998, 37, 1934.

5 G. Bottari, G. de la Torre, D. M. Guldi, T. Torres, Chem. Rev,. 2010, DOI: $10.1021 / \mathrm{cr} 900254 \mathrm{z}$.

${ }^{6}$ a) J. Baffreau, S. Leroy-Lhez, Van Anh, R. M. Williams, P. Hudhomme Chem. Eur. J., 2008, 14, 4974, b) J. Baffreau, S. Leroy-Lhez, P. Hudhomme, M. M. Groeneveld, I. H. M. van Stokkum, R. M. Williams J. Phys. Chem A, 2006, 110, 13123-13125, c) R. Gomez, J.L. Segura, N. Martin, Org. Lett. 2005, 7, 717.

${ }^{7}$ a) R. S. Lepkowicz, O. V. Przhonska, J. M. Hales, J. Fu, D. J. Hagan, E. W. Van Stryland, M. V. Bondar, Y. L. Slominsky, A. D. Kachkovski, Chem. Phys. 2004, 305, 259, b) P.-A. Bouit, C. Aronica, L. Toupet, B. Le Guennic, C. Andraud, O. Maury J. Am. Chem. Soc., 2010, 132, 4328.
${ }^{8}$ P.-A. Bouit,.F. Spänig, G. Kuzmanich, E. Krokos, C. Oelsner, M. A. Garcia Garibay, J. L. Delgado, N. Martín, and D. M. Guldi, Chem. Eur. J., 2010, 16, 9638.

9 a) D. LeGourrierec, M. Andersson, J. Davidsson, E. Mukhtar, L. Sun, L. Hammarstrom, J. Phys. Chem. A ,1999, 103, 557. b) J. Petersson, M. Eklund, J. Davidsson, L. Hammarström, J. Am. Chem. Soc. 2009, 131, 7940.

${ }^{10}$ P.-A. Bouit, D. Rauh, S. Neugebauer, J. L. Delgado, E. Di Piazza, S. Rigaut, O. Maury, C. Andraud, V. Dyakonov, N. Martín, Org. Lett., 2009, 11, 4806.

${ }^{11}$ P.-A. Bouit, E. Di Piazza, S. Rigaut, L. Toupet, C. Aronica, B. Le Guennic, C. Andraud, O. Maury, Org. Lett., 2008, 10, 4159.

12 a) M. Maggini, G. Scorrano, M. Prato, J. Am. Chem. Soc., 1993, 115, 9798; b) M. Prato, M. Maggini, Acc. Chem. Res., 1998, 31, 519; c) N. Tagmatarchis, M. Prato, Synlett, 2003, 768. 